Grammatical gender in Norwegian: Language acquisition and language change

\title{
Yulia Rodina
}

University of Oslo

Department of Linguistics and Scandinavian Studies / MultiLing

Postbox 1102 Blindern, 0315 Oslo

NORWAY

E-mail: yulia.rodina@,iln.uio.no

\section{Marit Westergaard}

UiT - The Arctic University of Norway

Department of Language and Linguistics / CASTL

N-9037 Tromsø

NORWAY

E-mail: marit.westergaard@uit.no 
Based on data from two experimental studies, this paper investigates the production of gender in a Norwegian dialect (Tromsø) by several groups of child and adult speakers. The findings show that gender is late acquired (around age 7) and furthermore, that there is a considerable difference between the groups, indicating an ongoing historical change involving the loss of feminine gender agreement. However, the feminine declensional endings are retained, e.g., the suffixal definite article. While there are sociolinguistic factors causing this change, we argue that the nature of the change can be explained by the process of language acquisition.

\section{Introduction.}

In this paper we present some new experimental data on gender agreement in a Norwegian dialect (Tromsø), collected from several groups of speakers: adults, teenagers, and three different groups of children. Our findings show spectacular differences between the groups, indicating that there is a surprisingly rapid change taking place in the dialect, involving the loss of feminine gender marking on the indefinite article and possibly the loss of feminine gender altogether. This means that the traditional three-gender system (masculine, feminine, neuter) is replaced by a twogender system (common, neuter). The cause of this change is presumably linked to extensive dialect contact and other sociolinguistic factors, but we argue that the nature of the change can be explained as a result of the acquisition process.

More specifically we argue that out of the three genders, the feminine is the most vulnerable due to low frequency and extensive syncretism in the morphological paradigm with the masculine, which has been argued to be the default gender. Furthermore, we show that the acquisition of the nominal inflectional suffixes is considerably less problematic than the acquisition of gender agreement, in that there is massive overgeneralization of the masculine indefinite article in the feminine and neuter, while the definite article (which is a suffix) is typically in place from early on. Our findings thus support the distinction between declension class and gender in Norwegian suggested by e.g., Enger (2004) and Lødrup (2011). This means that the definite article is typically unaffected by the change. The result of this process is a simplification in the gender system (from three to two), which is accompanied by added complexity in the declension system (in that the new common gender has two different declensional classes).

The paper is organized as follows: In the next section we briefly outline the traditional three-gender system of Norwegian and also provide some historical and sociolinguistic background. In section 3 we give an overview of some relevant previous research on the acquisition of gender in various languages, including some recent studies on the acquisition of gender in Norwegian in bilingual as well as monolingual contexts (Rodina \& Westergaard 2013a, b). Section 4 provides the research questions and a detailed description of the methodology of the present study, while sections 5 and 6 give an overview of the results of the experimental data. In section 7 we discuss our findings in terms of processes in language acquisition and change, and section 8 is a brief conclusion.

\section{Background.}

\subsection{The gender system of Norwegian (Tromsø dialect).}

We take the relatively standard approach to gender expressed in the much cited definition in Hockett 1958:231: "Genders are classes of nouns reflected in the behavior 
of associated words." This means that gender is a morphosyntactic feature expressed as agreement between the noun and other targets, e.g., determiners, verbs, and adjectives. Affixes on the noun itself, expressing e.g. definiteness or case, are considered to be part of the declensional paradigm. Thus, although affixes may differ across noun classes (and therefore across genders), they are not exponents of gender by themselves (Corbett 1991:146). In this paper, we therefore use the term agreement generally to mean the relationship between a noun and other targets, e.g., determiner-noun agreement as in et $h u s_{(\mathrm{N})}$ 'a house'. We also make a distinction between gender agreement and concord. Concord refers to agreement correspondence across several different targets, e.g., an indefinite article and an adjective as in $\boldsymbol{e t}_{N} \boldsymbol{g r o n t}_{N} \boldsymbol{h u s}_{(\mathrm{N})}$ ' a green house'. In sections 4.3, 5.3 and 7 concord is also contrasted with discord, i.e., non-correspondence between different targets as in $\boldsymbol{e n}_{\boldsymbol{M}} \boldsymbol{g r o n t}_{\boldsymbol{N}} h u \boldsymbol{s}_{(\mathrm{N})}$.

The two written standards of Norwegian, bokmål and nynorsk, both have a threegender system with distinctions between masculine, feminine and neuter. The bokmail standard also allows a two-gender system consisting of just common and neuter gender (see section 2.2). Just like most spoken varieties of Norwegian (see below for exceptions), the Tromsø dialect also traditionally has a three-gender system. Gender is mainly expressed within the DP, on adjectives and determiners (i.e., articles, demonstratives, and possessives). ${ }^{1}$ This applies only in the singular, as gender agreement is neutralized in the plural, e.g. fine biler ${ }_{M}$, fine bøker $F$, fine hus ${ }_{N}$ 'nice cars, nice books, nice houses'. Table 1 gives an overview of the parts of the gender system that are relevant for the present study, illustrated by the morphology of the Tromsø dialect. ${ }^{2}$

\begin{tabular}{|c|c|c|c|c|}
\hline \multicolumn{2}{|c|}{ Gender } & Masculine & Feminine & Neuter \\
\hline \multirow[t]{5}{*}{$\mathrm{SG}$} & Indefinite & en hest $a$ horse & ei seng $a$ bed & et hus a house \\
\hline & Definite & hesten horse.DEF & senga bed.DEF & huset house.DEF \\
\hline & $\begin{array}{l}\text { Double } \\
\text { definite }\end{array}$ & $\begin{array}{l}\text { den hesten } \\
\text { that horse.DEF }\end{array}$ & $\begin{array}{l}\text { den senga } \\
\text { that bed.DEF }\end{array}$ & $\begin{array}{l}\text { det huset } \\
\text { that house.DEF }\end{array}$ \\
\hline & Adjective & $\begin{array}{l}\text { en fin hest } \\
\text { a nice horse }\end{array}$ & $\begin{array}{l}\text { ei fin seng } \\
\text { a nice bed }\end{array}$ & $\begin{array}{l}\text { et fint hus } \\
\text { a nice house }\end{array}$ \\
\hline & Possessive & $\begin{array}{l}\min \text { hest/hesten } \min \\
\text { my horse }\end{array}$ & $\begin{array}{l}\text { mi seng/senga mi } \\
\text { my bed }\end{array}$ & $\begin{array}{l}\text { mitt hus/huset } \\
\text { mitt } \\
\text { my house }\end{array}$ \\
\hline
\end{tabular}

Table 1. The traditional gender system of Norwegian (Tromsø dialect).

As shown in Table 1, the indefinite article expresses a three-way gender distinction, with en for masculine, ei for feminine, and et for neuter. This also applies to the possessives (which may be both pre- and postnominal), with the forms $\mathrm{min}$, mi and mitt in the $1^{\text {st }}$ person singular $\left(2^{\text {nd }}\right.$ person $d i n$, di, ditt, $3^{\text {rd }}$ person $\sin$, si, sitt $)$. For virtually all adjectives there is syncretism between the masculine and feminine forms, e.g., fin 'nice'

\footnotetext{
${ }^{1}$ Gender agreement is also expressed outside the DP on predicate adjectives, e.g., bilen $_{(M)} \mathrm{er}$ grønn $_{M}$ 'the car is green', huset $(N)$ er grønt ${ }_{N}$ 'the house is green'. The focus in this paper is on DP-internal agreement, as illustrated in Table 1.

${ }^{2}$ As in most spoken varieties of Norwegian, the final $-t$ in the neuter definite article $-e t$ and the prenominal determiner det is silent in the Tromsø dialect.
} 
in the masculine and feminine vs. fint in the neuter. ${ }^{3}$ The definite article in Norwegian is a suffix, i.e., -en for masculine, - $a$ for feminine, and -et for neuter. Some traditional grammars treat the definite article as an expression of gender (e.g., Faarlund, Lie \& Vannebo 1997), but according to the definition given above, the definite suffixes should be considered to be expressions of declension classes instead (see also Enger 2004, Lødrup 2011). ${ }^{4}$ When a DP is demonstrative or modified (e.g., by an adjective, as in den røde bilen 'the red car'), definiteness is normally expressed twice, on a prenominal determiner as well as on the suffix. Syncretism between the masculine and feminine is found also on the prenominal determiner in double definite forms, i.e., den for masculine and feminine vs. det for the neuter. This is also the case for demonstratives (not shown in the table), e.g. denne bilen $_{M}$, denne boka ${ }_{F}$, dette huset ${ }_{N}$ 'this car, this book, this house', as well as certain quantifiers, e.g., all maten ${ }_{M}$, all suppa ${ }_{F}$, alt rotet ${ }_{N}$ 'all the food, all the soup, all the mess'. In the experiments discussed in the present paper, we focus on forms expressing gender proper (agreement with the noun) and forms expressing declension, more specifically indefinite articles and prenominal determiners in double definite DPs on the one hand, and definite suffixes on the other.

Gender assignment in Norwegian is traditionally viewed as non-transparent, as nouns do not provide reliable gender cues. This is in contrast to languages such as Spanish or Italian, where gender is highly predictable from morphophonological endings, i.e., $-o$ for masculine and $-a$ for feminine. Nevertheless, Trosterud (2001) has argued that $94 \%$ of all nouns may be accounted for by 43 different assignment rules: three general rules, 28 semantic rules, nine morphological rules and three phonological rules. He also argues that masculine is the default gender, i.e., the gender that will be assigned if no rule may be applied. Unfortunately, these rules are not very helpful from the perspective of language acquisition, as they typically have a high number of exceptions and also cover many classes of nouns that are infrequent in the input to children. In fact, children's sensitivity to some of these cues have been tested in Gagliardi 2012 with negative results (more on this in section 3). Nevertheless, three rules have been argued to have especially high predictability: Male human (for masculine gender), female human (for feminine gender), and final $-e$, a morphophonological cue for feminine. The latter cue is somewhat different in the (traditional) Tromsø dialect, as feminines ending in $-e$ in most varieties of Norwegian end in $-a$ in dialects spoken in and around Tromsø (i.e., Troms county). This means that there is no difference between the indefinite and definite forms of these nouns in the dialect, e.g., ei dama - dama 'a lady - the lady.' As discussed in Rodina \& Westergaard 2013a, there seems to be a change going on in Tromsø in that the four children investigated in that study (all born in 1992) use the two endings interchangeably in the indefinite, e.g., both $d u k k e$ and $d u k k a$ 'doll'. The significance of this for the present study is discussed in section 7 .

Trosterud (2001) has carried out a frequency count based on a total of 31,500 nouns in the Nynorsk Dictionary: Masculine nouns clearly constitute the majority of nouns, $52 \%$, while feminine nouns make up $32 \%$, and neuter nouns only $16 \%$. To our knowledge, there exists no frequency analysis based on natural spoken discourse or child-directed speech. Since frequency is an important factor in acquisition, it is crucial for our research that we have an indication of what the input to children is like. We have

\footnotetext{
${ }^{3}$ Only one exceptional adjective distinguishes between all three genders, viz. liten $_{M}$, lita $_{F}$, lite $_{N}$ 'little'. We will not be concerned with adjective agreement in this article.

${ }^{4}$ The reason why the definite suffix is traditionally considered to be a gender form is that it is derived diachronically from demonstratives, which were marked for gender agreement.
} 
therefore carried out a simple frequency investigation in a corpus of child language recorded in Tromsø (Anderssen 2006). The corpus consists of altogether 70 recordings of three children (age approximately $1 ; 8$ to $3 ; 3$ ) in conversations with their parents and the investigators, altogether eight adults. We have done a search for the indefinite articles (en, ei, et) in the data of some of the adults, so that every single file in the corpus has been investigated. Table 2 shows the frequency of the three indefinite articles for the following adults: The mother (MOT) in the Ann corpus, the investigator and the mother (INV, MOT) in the Ina corpus, and the father, mother and investigator (FAT, MOT, INV) in the Ole corpus.

\begin{tabular}{|l|l|l|l|}
\hline Adult/Files & MASCULINE $(\boldsymbol{e n})$ & FEMININE $(\boldsymbol{e i})$ & NEUTER $(e \boldsymbol{t})$ \\
\hline MOT Ann.01-21 & $195(69.9 \%)$ & $48(17.2 \%)$ & $36(12.9 \%)$ \\
\hline INV Ina.01-27 & $832(58.8 \%)$ & $289(20.4 \%)$ & $295(20.8 \%)$ \\
\hline MOT Ina 01-27 & $338(63.5 \%)$ & $132(24.8 \%)$ & $62(11.7 \%)$ \\
\hline FAT Ole.01-22 & $85(78.7 \%)$ & $15(13.9 \%)$ & $8(7.4 \%)$ \\
\hline MOT Ole.01-22 & $73(70.9 \%)$ & $8(7.8 \%)$ & $22(21.3 \%)$ \\
\hline INV Ole.14-22 & $343(64.2 \%)$ & $71(13.3 \%)$ & $120(22.5 \%)$ \\
\hline TOTAL & $1866(62.6 \%)$ & $563(18.9 \%)$ & $551(18.5 \%)$ \\
\hline
\end{tabular}

Table 2. The frequency of the three indefinite articles in adult data from the Troms $\varnothing$ acquisition corpus (Anderssen 2006).

The figures in Table 2 show that the frequency counts from the dictionary only partly hold up when we consider typical child-directed speech. That is, the masculine is even more frequently attested in children's input than in the dictionary $(62.6 \% \mathrm{vs} .53 \%)$ while the feminine is less frequently attested (18.9\% vs. $32 \%)$. It also shows that there is no difference in frequency between the feminine and the neuter. Our investigation has only counted token frequencies for the indefinite article, not type frequencies of the corresponding nouns. However, we believes that this gives a relatively correct picture of what a Norwegian child is typically exposed to, as we have studied six different adults speaking to three different children across 70 different recordings.

\subsection{A brief historical, geographical, and sociolinguistic perspective.}

Speakers of Norwegian generally speak their dialects in all situations, formal and informal. The written language has two standards, bokmål and nynorsk (see Venås 1993 and Vikør 1995 for more information about the language situation in Norway). The bokmal variety is built on the Danish language that was the written standard at the time of Norwegian independence in 1814, and the present-day version of it is the result of a number of adaptations and Norwegianizations of Danish taking place since the first orthographic reform in 1907. Nynorsk, on the other hand, is a written standard based on Norwegian dialects, created by the philologist, lexicographer, and poet Ivar Aasen in the mid- $19^{\text {th }}$ century in order to be a real Norwegian alternative to written Danish. While nynorsk is mainly used in the Western part of the country, the bokmål variety is by far the more commonly used standard in Norway. In Troms county, where our investigation took place, as much as $95 \%$ of the population use bokmål as their main written standard (http://www.riksmalsforbundet.no/Statistikk.aspx).

The three-gender system of Proto-Germanic has been lost in several of the presentday Germanic languages, including Dutch, Swedish, and Danish. These languages have generally lost the feminine gender and have developed a two-gender system consisting of common gender (masculine/feminine) and neuter. As Danish has a two-gender 
system, the bokmål written standard allows the use of only two genders, although the three-gender system of most spoken varieties has been introduced as an alternative. This means that nouns that are feminine in the spoken language may be used with either feminine or masculine (i.e., common) declensions and gender agreement in written bokmål, as shown in 1 . The version in $1 \mathrm{~b}$ signals a somewhat more formal style.
a. $\quad$ ei bok
- boka
a.FEM book(FEM)
- book.DEF
b.
en bok - boken
a.COMM book(COMM) - book.DEF
'A book - the book.'
(Norwegian, bokmål)

Most dialects (and consequently also the nynorsk standard) have retained the threegender system. The only exception to this is the Bergen dialect, which underwent a change from a three- to a two-gender system already centuries ago, arguably due to extensive language contact with low German during the Hansa period (see e.g., Jahr 1998; 2001, Trudgill 2013). This means that the Bergen dialect only allows 1b. The forms in $1 \mathrm{~b}$ were also used in a spoken variety called the 'educated casual style' [Norwegian: den dannede dagligtale] (Torp 2005:1428), used by the upper classes in the $19^{\text {th }}$ century (Haugen 1966:31). This variety was a compromise between Eastern Norwegian urban dialects and a Norwegian reading pronunciation of Danish.

More recently, Lødrup (2011) has attested loss of the feminine also in the speech of people from other parts of Oslo. He attributes this to the spread of the 'educated casual style', which has influenced the traditional Oslo dialect. Lødrup has studied a corpus of adult speech consisting of altogether 142 speakers, finding that there is a difference between the age groups, the older speakers using very little feminine gender and the younger speakers hardly at all. He also finds that, while the indefinite article $e i$ (feminine) is very infrequent in the data, the speakers generally still use the declensional endings of the feminine, e.g., the $-a$ suffix of the definite article. ${ }^{5}$ This means that the pattern is the following (compare with example 1 above):

$$
\begin{aligned}
& \text { en bok } \quad-\text { boka } \\
& \text { a.COMM book (COMM) - book.DEF } \\
& \text { 'A book - the book.' }
\end{aligned}
$$

Finally in this section, we would like to mention that Conzett, Johansen \& Sollid (2011) have attested a similar pattern in certain dialects in North Norway (Kåfjord and Nordreisa), spoken in areas approximately 150 kilometers north of Tromsø. This region has had extensive language contact with Saami and Kven, languages which do not have grammatical gender. ${ }^{6}$ This language contact is argued to have caused a reduction of the gender system of the Norwegian spoken in this area from three to two, while the declension system is generally intact. This means that also here, the gender and declension system of previously feminine nouns is generally as illustrated in 2 .

\footnotetext{
${ }^{5}$ The situation in Oslo is somewhat more complicated than this, in that there is also considerable variation between the $-a$ and the -en suffixes dependent on noun type as well as individual speaker preferences. It should be mentioned that the bokmål written standard also allows the pattern in (2), in addition to $(1 \mathrm{a}, \mathrm{b})$.

${ }^{6}$ Kven is the language spoken in certain areas of North Norway by descendants of Finnish immigrants.
} 


\section{Previous acquisition research.}

The acquisition of gender in Norwegian is largely understudied. Some early facts are reported by Plunkett \& Strömquist (1992) based on longitudinal data of one Norwegian child (age 2;3-2;5) acquiring the Western Oslo dialect, which only has two genders (data from Vanvik 1971). Like the Swedish and Danish children also discussed by Plunkett \& Strömquist, the Norwegian child is found to produce occasional errors involving overgeneralization of common gender to neuter nouns, as shown by the following examples: In 3, both the definite suffix and the possessive determiner are non-targetconsistently marked for common gender; in 4 the suffix is correctly marked for neuter while the possessive is not. While Plunkett \& Strömquist only provide a few examples and no statistical evidence, these findings nevertheless indicate that gender agreement may be more vulnerable in acquisition than declensions (suffixes).

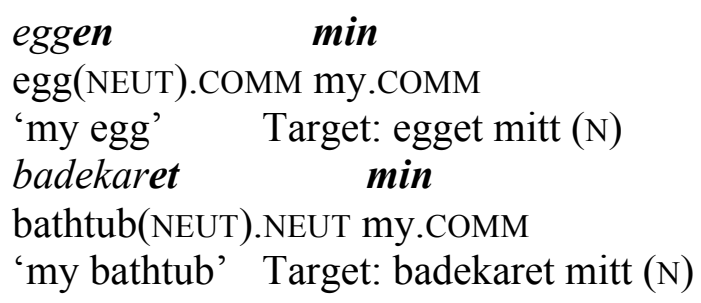

More recently, Rodina \& Westergaard (2013a) have conducted a detailed analysis of some longitudinal data from the Tromsø corpus (Anderssen 2006) of two bilingual Norwegian-English children as well as two monolingual children used as controls: Ina (age range 2;10-3;3) and Ole (age range 2;6-2;10), both born in 1992. The examination of the children's accuracy with indefinite articles, adjectives, possessives, and prenominal determiners in double definites reveals that the acquisition of gender agreement is delayed in all four children's data compared to what is typically the case in other languages. The findings also show that the neuter gender is most vulnerable. For example, with indefinite DPs, which are the most problematic forms, Ina makes no errors in the masculine, but $57.8 \%$ errors in the feminine and as much as $92.6 \%$ in the neuter. Ole makes $1.7 \%, 12.5 \%$ and $21.4 \%$ errors with the masculine, feminine and neuter genders respectively. As we see from these numbers, there are considerable individual differences between the children (and furthermore, there is no clear difference between monolinguals and bilinguals). A qualitative analysis shows that all the children mainly overgeneralize masculine gender forms with both feminine and neuter nouns. At the same time, a discrepancy is found between the acquisition of gender agreement (e.g., the indefinite article) and gender marking on suffixes (e.g., definite articles). This is illustrated in examples 5-6 from Ole's data: In 5 he produces masculine gender agreement on a neuter noun, while in 6 , which is from the same recording, he uses the target-consistent definite suffix on the same noun. This indicates that the distinction between declension vs. gender marking in Norwegian may receive some psycholinguistic support from acquisition.

$$
\begin{aligned}
& \text { en fly } \\
& \text { a.M plane.N } \\
& \text { 'a plane' Target: et fly } \\
& \text { inni flyet } \\
& \text { in plane.DEF.N } \\
& \text { 'in the plane' }
\end{aligned}
$$


Further research evidence on the acquisition of gender by somewhat older children acquiring the Tromsø dialect is provided in Rodina \& Westergaard 2013b. This is an experimental study focusing on bilingual Norwegian-Russian children, and including a control group of nine monolinguals with a mean age of 4;4, born around 2008. These children are also shown to overgeneralize masculine gender forms to the feminine and the neuter. However, in this group, it is the feminines that are most problematic: The error rate with the feminine is as high as $99 \%$ for indefinite articles, while the corresponding error rate for neuter is considerably lower, $49 \%$. Thus, according to Rodina \& Westergaard 2013b neither feminine nor neuter gender is acquired by the age of 4 .

Finally in this section, we consider the data in Gagliardi 2012, elicited from even older children: nine in daycare (mean age 5;1) and 11 in school (mean age 6;8). Gagliardi (2012) is primarily concerned with how monolingual speakers of the Tromsø dialect use what she refers to as noun-internal and noun-external distributional information to assign gender to existing as well as novel nouns. With regard to nouninternal information, she identifies three gender cues that have been argued to have the most predictive power: male human for masculine, and female human and final $-e$ for feminine (see section 2.1). In the gender assignment task with existing nouns, Gagliardi observed that feminine nouns are more problematic than masculine and neuter in the speech of these preschool and school children. The error rates with the feminines range between $35 \%$ and $53 \%$ depending on the cue (35\% errors for the semantic cue, $46 \%$ for the phonological cue, and 53\% for no cue). These errors with the feminines are due to overgeneralization of the masculine gender forms. At the same time, neuter and especially masculine nouns are virtually error-free in the children's data $(6 \%$ and $5 \%$ errors respectively). Furthermore, in the task with novel nouns, Gagliardi observed that the children are not sensitive to the two gender cues for feminine. In this case, neither internal nor external information (i.e., indefinite articles provided by the experimenter) prevented massive overgeneralization of masculine gender.

In summary, the studies reviewed in this section show that grammatical gender is a late acquired phenomenon in Norwegian, presumably due to the lack of transparency in gender assignment. Gender seems to be highly problematic for monolingual children at least until the age of six. So far, there are no studies showing when gender knowledge becomes target-like. Furthermore, it is not clear what aspects of gender are most problematic for Norwegian-speaking children: While Rodina \& Westergaard (2013a) suggest that neuter is most vulnerable in 2-3-year-olds, Gagliardi (2012) and Rodina \& Westergaard (2013b) observe that 4-6-year-olds have greater problems with the feminine. The existing research also suggests that gender agreement is considerably more complex than the declension system in the acquisition process. Finally, the high error rates at relatively late stages of acquisition could suggest that these gender facts may never be acquired by these children and that what we are really seeing is a language change in progress, involving the loss of the feminine. An important point in this respect is that the corpus data investigated in Rodina \& Westergaard's (2013a) study is from children who are born 16 years earlier than the children investigated in Rodina \& Westergaard 2013b. These unresolved issues are the main focus of the present study.

\section{The present study: Research questions and methodology.}

\subsection{Research questions and goals.}

This study had two main goals. Our first goal was to reveal what aspects of the Norwegian gender system are most problematic for children acquiring the Tromsø 
dialect, and how long these problems persist. In order to answer these questions we originally wanted to compare children's knowledge of masculine, feminine, and neuter gender before and after the age of six (5-6-year-olds and 7-8-year-olds). As our initial findings showed that the gender problems persisted in the older age group, we decided to investigate a group of even older children (age 11-13) as well as a group of teenagers (age 18-19). We also performed the same experiments on adults, in order to control for the input that children growing up in Tromsø typically receive from their parents and other caregivers.

Given that the feminine may be most vulnerable in the gender system of the Troms $\varnothing$ dialect, it is also necessary to investigate the status of different feminine nouns more closely. Thus, our second goal is to find out whether feminine is only late acquired or in the process of being lost. Recall that in the previous experimental studies, 4-year-olds were found to make $99 \%$ errors with feminine nouns (Rodina \& Westergaard 2013b), while in Gagliardi's (2012) study, 4-7-year-olds make between 35\% and 53\% errors. This suggests that the feminine gender may be a late acquired phenomenon and that it does fall into place eventually. However, given that the studies use different methodologies, they are not directly comparable, and we would therefore like to test different age groups (including adults) using the same experimental method.

Furthermore, we investigate whether the use of feminine agreement can be facilitated by semantic and/or morphophonological cues which have been argued to have predictive power, i.e., female human and final -e (see Trosterud 2001). The latter cue would correspond to final $-a$ in the traditional Tromsø dialect (see section 2.1).

According to Gagliardi (2012), the semantic cue may have a stronger facilitating effect than the morphophonological cue, as the children in her study make fewer errors with existing nouns denoting females than with feminine nouns ending in $-e$ (35\% vs. $46 \%)$. Investigating this issue will also contribute to the debate on the importance of semantic vs. morphophonological cues in gender acquisition. Based on data from various languages, it has been shown that morphophonological cues are more important for children at early ages and that semantic rules take over later in development (KarmiloffSmith 1979; Mills 1981; Levy 1983; Rodina \& Westergaard 2012; Rodina 2013). The languages considered in these studies - French, German, Hebrew, Russian - have gender systems where gender assignment could be argued to be (more or less) rule based. $^{7}$

The last issue that we address in the present study is the distinction between gender agreement (between the noun and other targets) and declension marking (on the noun itself). In previous acquisition studies (Rodina \& Westergaard 2013a, 2013b), it was found that, although gender agreement is problematic for children for an extended period of time, declensional suffixes such as the definite article are in place from early on. In Lødrup 2011 and Conzett, Johansen \& Sollid 2011, who both report on a change from a three- to a two-gender system, it is shown that the change generally only affects gender, but not the declensional endings. Thus, in our present study, we test both agreement and declension.

Our research questions are summarized as follows:

\footnotetext{
${ }^{7}$ As pointed out by two anonymous reviewers, some recent accounts argue that the gender systems of French and German are rather arbitrary (see e.g. Kupisch, Müller \& Cantone 2002; Hopp 2012). It would be necessary to test speakers' sensitivity to particular gender cues to resolve this issue. In the case of Norwegian, the arbitrariness of the gender system has been shown by Gagliardi's (2012) experimental data.
} 
1. What aspects of the gender system of Norwegian are the most problematic to acquire?

2. When is gender acquired (at $90 \%$ accuracy)?

3 . Is there a distinction between gender and declension?

4. Are children sensitive to semantic and/or morphophonological cues in gender acquisition?

5. Is the feminine gender late acquired or in the process of being lost?

\subsection{Participants.}

The participants in the study were altogether 70 child and adult native speakers of the Tromsø dialect. They were divided into five groups according to age, as illustrated in Table 3. The child participants were born in Tromsø and grew up acquiring the local dialect. Some of the children had also been exposed to other Norwegian dialects at home. The adult participants were all born in Tromsø and had lived there most of their lives. They were employees at the University of Tromsø, but had no background in linguistics.

\begin{tabular}{|l|l|l|l|}
\hline Group description & Number & Age range & Mean age \\
\hline Group 1: Pre-school children & 15 & $3 ; 6-6 ; 0$ & $5 ; 2$ \\
\hline $\begin{array}{l}\text { Group 2: Elementary school } \\
\text { children (grades 1 \& 2) }\end{array}$ & 12 & $6 ; 6-8 ; 2$ & $7 ; 6$ \\
\hline $\begin{array}{l}\text { Group 3: Elementary school } \\
\text { children (grade 7) }\end{array}$ & 12 & $11 ; 9-12 ; 8$ & $12 ; 0$ \\
\hline Group 4: High school students & 17 & $18-19$ & 18 \\
\hline Group 5: Adults & 14 & $31-64$ & 53 \\
\hline
\end{tabular}

Table 3. Overview of the participant groups, specifying age in years;months for the children (Groups 1, $2 \& 3$ ) and years for the teenagers and adults (Groups 4 \& 5).

\subsection{Stimuli and procedure.}

In order to answer the research questions formulated in section 4.1, we conducted two elicited production experiments: one that focused on all three genders and another that focused on feminine nouns only. The second experiment tested both a semantic and a morphophonological cue. The same experimental design was used in both tasks. This is an adaptation of a research design used in Stöhr et al. 2012 and Rodina \& Westergaard $2013 \mathrm{~b}$. In both tasks the materials were a series of colored pictures showing various objects depicting the target nouns. The pictures were presented on a laptop computer and all responses were audio-recorded. In order to compare gender marking on free vs. bound morphemes (i.e., agreement vs. declension), we elicited indefinite and double definite DPs in the same experimental setting. An example of the elicitation procedure is illustrated in 7.

(7) (Pictures of a yellow and a red car shown simultaneously on the screen)

Experimenter: Dette kalle vi for bil. Korsen farge e dem?

This we call car. What color are they?

Expected response 1: En gul bil og en rød bil a.M yellow car(M) and a.M red car(M)

(The red car disappears - picture of a yellow car remains) 
$\begin{array}{ll}\text { Experimenter: } & \text { Ka som forsvant? } \\ & \text { What disappeared? }\end{array}$

Expected response 2: den røde bilen

the.M red car.DEF(M)

the red car

The lead-in statement in 7 was carefully chosen in order not to reveal the gender of the target noun. The sentences in 8 illustrate the corresponding responses expected for feminine and neuter nouns.
a. ei gul flaske og ei rød flaske-den røde flaska
a yellow bottle and a red bottle - the red bottle
b. et gult tog og et rødt tog - det røde toget
a yellow train and a red train - the red train

Note that the experiment tests three gender forms for each item, the indefinite article, the adjective, and the prenominal determiner in the double definite DPs. This means that our study could in principle also address the question of gender assignment vs. gender agreement, as defined in many recent acquisition studies on languages such as Italian and German, e.g., Bianchi (2013) and Kupisch, Akpinar \& Stöhr (2013): In cases where there is non-target-consistent agreement between the noun and the other target forms, correspondence between the different forms (concord) has been used to argue that the problem is in gender assignment, while non-correspondence (discord) indicates that the problem is with agreement. However, this issue is not part of our main research focus, as the nature of the Norwegian gender system (see section 2.1) gives us reason to expect children to have problems with assignment rather than agreement. That is, gender assignment is generally non-transparent and has been found in previous studies to be late acquired (Rodina \& Westergaard 2013a, b), while the concord between different target forms is relatively uncomplicated (e.g., there are no case forms). Thus, we will assume that discord between the different targets, especially if this appears only occasionally, will indicate that there is a problem with assignment rather than agreement, in the sense that children are unsure about the gender and therefore vacillate between different forms. We return to this issue briefly in sections 5.3 and 7 .

In Experiment 1 we included 24 nouns distributed equally among the three genders, i.e., eight masculine, eight feminine, and eight neuter nouns. The test items were presented in a randomized order preceded by a training session with three nouns, one from each gender. As shown in examples 7-8, the objects were contrasted with respect to color.

In Experiment 2 we included 24 feminine nouns distributed equally between four subtypes of feminines: nouns denoting females with a zero ending (ei heks 'a witch'), non-females ending in - $e$ (ei flaske 'a bottle'), nouns with both cues, i.e., denoting females and ending in - $e$ (ei dame 'a lady'), and nouns with neither cue, i.e., denoting non-females and with a zero ending ( $e i$ and 'a duck'). Note that in the traditional Troms $\varnothing$ dialect, the nouns ending in $-e$ would be pronounced with a final $-a$, i.e., $e i$ flaska 'a bottle' and ei dama 'a lady'. Six neuter nouns were used as fillers. Importantly, no masculine nouns were included in the test, as we wanted to avoid any possible effect of priming. The objects in Experiment 2 were contrasted with respect to both color and size. 
The experiments were carried out by two investigators, a native speaker of Norwegian working as a research assistant and an advanced second language speaker of Norwegian (the first author of this paper). The order of the experiments varied, so that one group of participants performed Experiment 1 first, while the other group performed Experiment 2 first. If the participants did not use the correct color or scalar adjective in their responses, they were never corrected. The experiments with the children were conducted in daycare centers and schools, individually in a quiet room. The experiments with the adults were conducted individually in the TROmsø Language acquisition Lab (TROLL). The adult speakers were told that the purpose of the task was to compare child and adult use of color and scalar adjectives with different nouns. This was done in order to ensure that they were not conscious of the grammatical phenomenon tested.

The recordings were transcribed by a research assistant who is a native speaker of Norwegian. We counted responses with indefinite articles, prenominal determiners and suffixed definite articles separately. It should be noted that the number of expected responses varied for different agreement targets. In both experiments, a total of 48 responses were expected with indefinite articles (two per test item) and 24 responses with double definite forms -24 prenominal determiners and 24 suffixed definite articles. In some cases, the target noun was missing in the response and only the indefinite article or prenominal determiner was used together with an attributive adjective, as shown in 910. Such responses are perfectly grammatical, and since the target noun was introduced in the immediately preceding context, they were included in the counts. We excluded responses where a different noun was used.

et grønt hus og et gult

a green house and a yellow

'A green house and a yellow one.'

et grønt hus - det grønne

a green house - the green

'A green house - the green one.'

\section{Results - Experiment 1: Masculine-Feminine-Neuter.}

\subsection{Indefinite DPs.}

Table 4 shows the accuracy of gender agreement on the indefinite article across the five groups of participants; Figure 1 displays the same results. It is clear that the children (Groups 1,2 and 3) do not have any problem with masculine nouns, producing the indefinite article en in virtually all cases. Feminine $e i$, on the other hand, is highly problematic and there is no increase in accuracy across the three age groups: The accuracy for the pre-school children is $15 \%$ and this decreases for the school children, to $9 \%$ and $7 \%$ in Groups 2 and 3 respectively. A binomial mixed effects model reveals no age effect in the three groups of children: $p=0.1$ and $p=0.2$ for Group 2 vs. 1 and Group 3 vs. 1 respectively. The adults in Group 5, on the other hand, use the feminine indefinite article $e i$ as often as $99 \%$, while the 18-19-year-olds (Group 4) constitute a middle group, using feminine ei $56 \%$. The same statistical model shows that the teenagers (Group 4) and adults (Group 5) are significantly different from the child participants: $p<0.05$ for both age groups.

Table 4 also shows that neuter is not completely target-consistent for the three groups of children, the preschoolers (Group 1) making 21\% errors and the older children in Groups 2 and 3 making occasional errors ( $8 \%$ in both groups), a proportion which does not exceed the $10 \%$ experimental error margin. Thus, there is an improvement with 
age in the three child groups. This turns out not to be statistically significant ( $p=0.9$ across the three age groups), which may be due to the generally high accuracy and the large age span within the groups. Nevertheless, the statistical analysis reveals that there is a clear effect of noun class, in that the children's accuracy rates for feminine $e i$ is significantly lower than for neuter et: $p<0.0001$ for Groups 1, 2 and 3.

\begin{tabular}{|l|l|l|l|}
\hline Group/Age & Masculine (en) & Feminine (ei) & Neuter (et) \\
\hline Group 1 & $98 \%$ & $15 \%$ & $79 \%$ \\
$3 ; 6-6 ; 0$ & $188 / 191$ & $23 / 155$ & $129 / 164$ \\
\hline Group 2 & $99 \%$ & $9 \%$ & $92 \%$ \\
$6 ; 6-8 ; 2$ & $149 / 151$ & $12 / 139$ & $128 / 139$ \\
\hline Group 3 & $100 \%$ & $7 \%$ & $92 \%$ \\
$11 ; 9-12 ; 8$ & $189 / 189$ & $12 / 171$ & $172 / 187$ \\
\hline Group 4 & $100 \%$ & $56 \%$ & $100 \%$ \\
$18-19$ & $272 / 272$ & $134 / 239$ & $265 / 265$ \\
\hline Group 5 & $100 \%$ & $99 \%$ & $100 \%$ \\
$31-64$ & $207 / 207$ & $192 / 194$ & $202 / 202$ \\
\hline
\end{tabular}

Table 4. Experiment 1: Accuracy of gender agreement on indefinite articles.

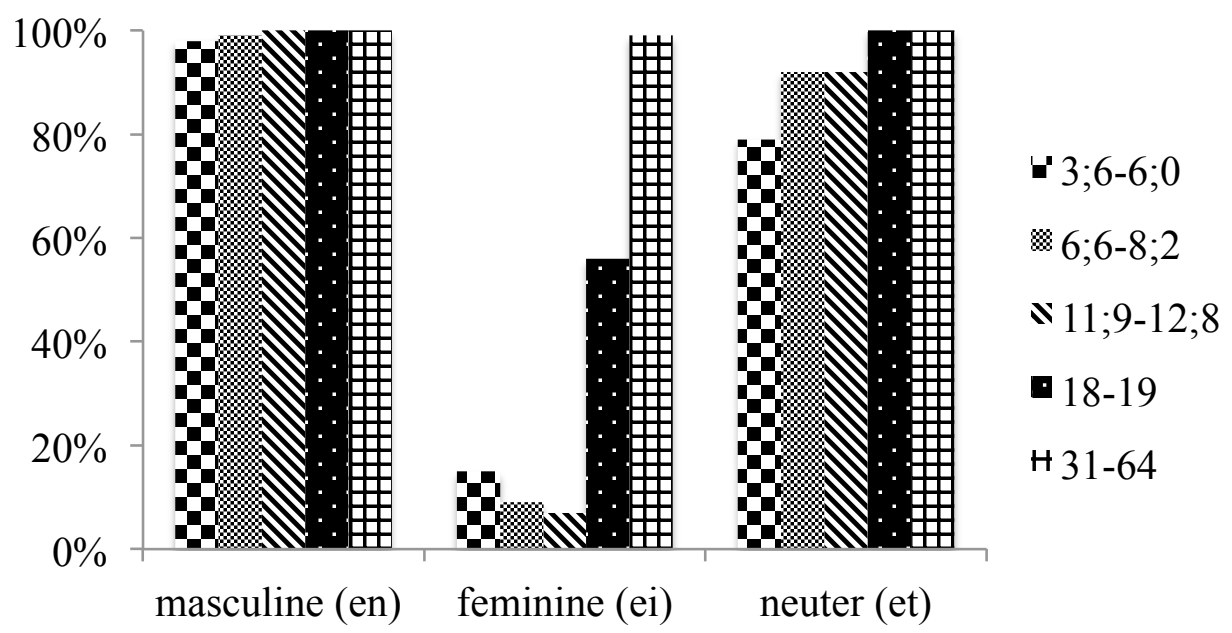

Figure 1. Experiment 1: Accuracy of gender agreement on indefinite articles.

The mistakes made by the children with feminine as well as neuter nouns are overgeneralization to the masculine gender, as demonstrated by the examples in 11. This confirms previous findings both from corpus and experimental data (Rodina \& Westergaard 2013a, b).

a. en blå kake

a.M blue cake(F)

Target: ei blå kake

b. en blå anker

a.M blue anchor(N)

Target: et blåt anker 
In order to try to establish the age at which neuter gender is fully mastered by these children, we divided our child participants in Groups 1 and 2 into three smaller groups: 3-4-year olds $(\mathrm{N}=9)$, 5-6-year-olds $(\mathrm{N}=8)$, and 7-8-year-olds $(\mathrm{N}=10)$. This allows us to follow the children's development with the neuter form et more closely over time. The accuracy rates for the respective subgroups are $82 \%, 79 \%$, and $91 \%$. The statistical analysis shows no age effect ( $p>0.3$ binomial mixed effects model). Nevertheless, the data suggest that neuter is unstable between the ages of 3 and 6, while there is a considerable increase of accuracy rates in the oldest group, the 7-8-year-olds. This can be taken as an indication that neuter is not fully mastered until the age of 7, i.e., when accuracy reaches a level above $90 \%$. This will also be supported by the results on the neuter prenominal determiner det discussed in section 5.2.

Finally, we need to consider the feminine nouns more closely, both with respect to individual speakers and specific nouns. The individual speaker preferences with the feminines are summarized in Table 5. As we see, the majority of the child speakers in Groups 1, 2, and 3 use the masculine form en exclusively (altogether 30/39), while three use only $e i$ and six use both forms. In contrast, all except one of the adult speakers in Group 5 (13/14) use only ei, and this one speaker uses both. Finally, among the 18-19year-olds (Group 4) five speakers use en exclusively, seven use only ei, and five use the two forms interchangeably.

\begin{tabular}{|l|l|l|l|}
\hline Group/Age & $\boldsymbol{e i}$ only & $\boldsymbol{e i}$ \& en & en only \\
\hline Group 1: 3;6-6;0 & $0 / 15$ & $6 / 15$ & $\mathbf{9 / 1 5}$ \\
\hline Group 2: 6;6-8;2 & $2 / 12$ & $0 / 12$ & $\mathbf{1 0} / \mathbf{1 2}$ \\
\hline Group 3: $11 ; 9-12 ; 8$ & $1 / 12$ & $0 / 12$ & $\mathbf{1 1 / 1 2}$ \\
\hline Group 4: $18-19$ & $\mathbf{7 / 1 7}$ & $5 / 17$ & $5 / 17$ \\
\hline Group 5: $31-64$ & $\mathbf{1 3 / 1 4}$ & $1 / 14$ & $0 / 14$ \\
\hline
\end{tabular}

Table 5. Experiment 1: The use of the indefinite article ei (FEM) and en (MASC) with feminine nouns, $N$ participants/Total.

This means that the majority of speakers (58/70) only use one of the forms, either masculine or feminine. A closer inspection of the 12 speakers who produce both $e i$ and en reveals that all of these also have clear preferences: The one adult speaker mixing the two forms produces only two occurrences of en, both of them with the same noun, thus displaying the same preference for the feminine as the other adults. The five teenagers (Group 4) who use both forms also turn out to clearly favor one of them, as two prefer the masculine and three the feminine. In Group 1, six of the pre-school children use a mixture of forms, only one of them showing a preference for the feminine, while the remaining five favor the masculine. Thus, out of the 12 participants who use a mixture of forms, five turn out to have a clear preference for the feminine (one adult, three teenagers, and one child in the youngest group), while the rest have a preference for the masculine (two teenagers and five of the youngest children). Furthermore, the occasional examples that deviate from the preference do not seem to be linked to any particular nouns in the experiment.

\subsection{Double definite DPs.}

In double definite DPs, we considered gender agreement on the prenominal determiner as well as the form of the declensional class marker on the definite suffix. Recall that while suffixes alternate between -en, $-a$, and -et for masculine, feminine, and neuter nouns respectively, there are only two forms of the prenominal determiner: den for 
masculine and feminine and det for neuter nouns. Given the syncretism between the masculine and feminine, it is not surprising that the children's accuracy rates are roughly $100 \%$ for the determiner den in all three age groups, as illustrated in Table 6 . There is thus no difference between child and adult speakers in this respect. The accuracy rate with the neuter form det, on the other hand, is somewhat lower for the youngest children (Group 1) - 79\%, which is identical to what was observed for the neuter indefinite article et (compare Table 4). Similarly, the accuracy rates with neuter det increase with age and reach the near-target level of $98 \%$ in Groups 2 and 3; yet, the differences between the three child age groups are not significant: $p=0.9$ (binomial mixed effects model). As expected, the errors in the neuter result from overgeneralization of common gender den.

\begin{tabular}{|l|l|l|l|l|l|l|}
\hline \multirow{2}{*}{ Group/Age } & \multicolumn{3}{l|}{ Masculine } & \multicolumn{2}{l|}{ Feminine } & Neuter \\
\cline { 2 - 7 } & den & - en & den & $-\boldsymbol{a}$ & det & -et \\
\hline Group 1 & $100 \%$ & $100 \%$ & $98 \%$ & $89 \%$ & $79 \%$ & $93 \%$ \\
$3 ; 6-6 ; 0$ & $114 / 114$ & $102 / 102$ & $99 / 101$ & $85 / 96$ & $85 / 108$ & $86 / 93$ \\
\hline Group 2 & $94 \%$ & $100 \%$ & $96 \%$ & $95 \%$ & $98 \%$ & $100 \%$ \\
$6 ; 6-8 ; 2$ & $73 / 78$ & $48 / 48$ & $72 / 75$ & $52 / 55$ & $80 / 82$ & $51 / 51$ \\
\hline Group 3 & $100 \%$ & $100 \%$ & $100 \%$ & $100 \%$ & $98 \%$ & $100 \%$ \\
$11 ; 9-12 ; 8$ & $89 / 89$ & $85 / 85$ & $93 / 93$ & $92 / 92$ & $89 / 91$ & $88 / 88$ \\
\hline Group 4 & $100 \%$ & $100 \%$ & $100 \%$ & $100 \%$ & $100 \%$ & $100 \%$ \\
$18-19$ & $121 / 121$ & $112 / 112$ & $130 / 130$ & $123 / 123$ & $133 / 133$ & $123 / 123$ \\
\hline Group 5 & $100 \%$ & $100 \%$ & $100 \%$ & $99 \%$ & $100 \%$ & $100 \%$ \\
31-64 & $107 / 107$ & $94 / 94$ & $107 / 107$ & $96 / 97$ & $109 / 109$ & $92 / 92$ \\
\hline
\end{tabular}

Table 6. Experiment 1: Accuracy of gender marking in double definite DPs, prenominal determiners and suffixes.

Table 6 also shows that the use of suffixes is unproblematic in the masculine, the accuracy rates being $100 \%$ across all participant groups. Moreover, the suffixes are produced at a target-consistent level also in the feminine and neuter, with only slightly lower accuracy rates for the youngest children, 89\% and 93\% (Group 1). This is in stark contrast to the performance on the indefinite article $e i$, which was used infrequently especially by the children (Groups 1, 2, 3), but also the teenagers (Group 4). A comparison of the accuracy rates in the feminine is illustrated in Figure 2, where the contrast between the indefinite article $e i$ and the suffixed definite article $-a$ is highly significant in Groups 1,2 , and 3 ( $p<0.0001$ for all three age groups). This result also confirms previous findings (Rodina \& Westergaard 2013a, b). 


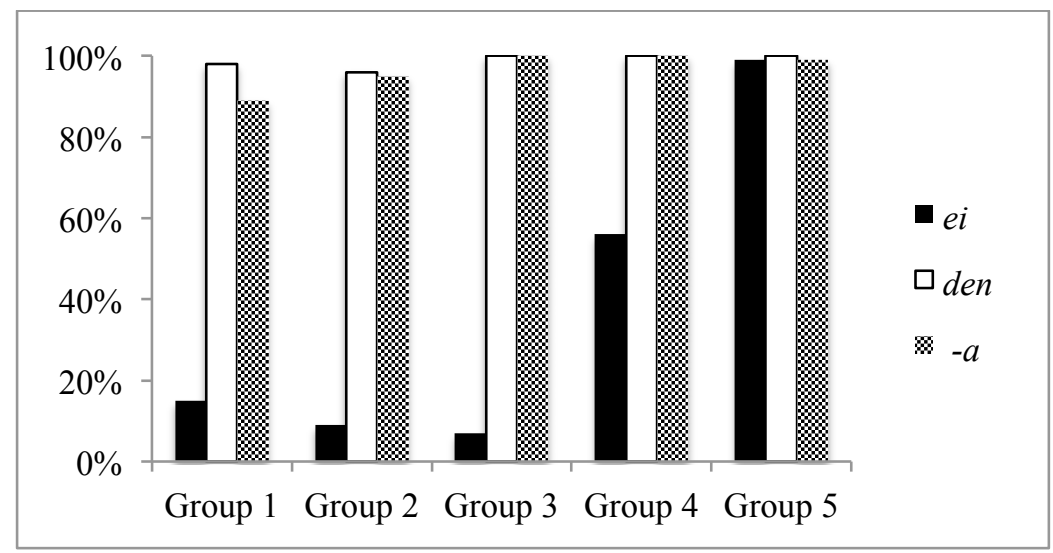

Figure 2. Experiment 1: Comparison of accuracy rates in the feminine.

In the neuter, illustrated in Figure 3, the accuracy for the suffixed definite article -et is contrasted with the accuracy for the indefinite article et. This is most striking in Group 1 and turns out to be highly significant $(p<0.0001)$. There is also a highly significant contrast between the suffix and the neuter prenominal determiner det in Group 1 ( $p=$ $0.005)$. Both types of contrast disappear already at the next stage, in Group 2 ( $p=0.995$ for et vs. $-e t$ and $p=0.984$ for $d e t$ vs. $-e t$ ).

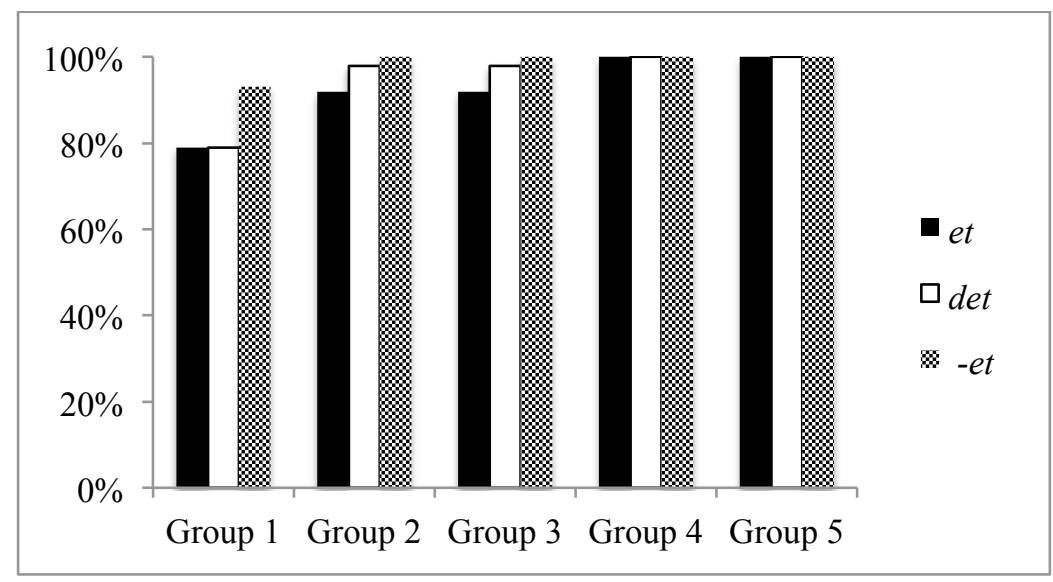

Figure 3. Experiment 1: Comparison of accuracy rates in the neuter.

The examples in 12-13 illustrate the contrast between gender marking on the indefinite article and the mastery of the declensional suffix with feminine and neuter nouns in the children's production. In both examples the child uses the masculine form of the indefinite article, but the correct suffix on the same lexical item. The pattern in 12 is characteristic of all children (Groups 1, $2 \& 3$ ) as well as the teenagers (Group 4).

a. en blå kake

a.M blue cake(F)

Target: ei blå kake

b. den blåe kaka

the.c blue cake(F)

a. en brun (gatelys)

a.M brown street light $(\mathrm{N})$ 
Target: et brunt gatelys
b. den brune gatelyset

(D10 5;1)

the.c brown street light $(\mathrm{N})$

Target: det brune gatelyset

In order to investigate the children's development with the neuter over time and to compare their gender marking on the prenominal determiner to the indefinite article, we again divided our child participants in Groups 1 and 2 into three smaller groups: 3-4year olds, 5-6-year-olds, and 7-8-year-olds. The accuracy rates are $80 \%, 82 \%$ and $97 \%$ in the three groups. This is similar to the developmental pattern for the indefinite article (see section 5.1). A binomial mixed-effects model also confirms that these differences are statistically significant: $p=0.0165$. On the basis of the similarities in the developmental pattern of the indefinite article and the prenominal determiner, we may conclude that neuter gender is mastered around the age of 7 .

\subsection{Gender concord vs. discord.}

In this section, we address the question of consistency of gender agreement across the different targets, i.e., what is often referred to as the issue of assignment vs. agreement (e.g., Bianchi 2013, Kupisch, Akpinar \& Stöhr 2013). As mentioned above (sections 2.1 and 4.3), we refer to this as concord vs. discord in the different agreement forms. A detailed investigation of the child data (Groups 1,2 and 3) in Experiment 1 reveals that, in the neuter nouns, there are 27/244 (11\%) examples of gender discord and 12/244 (5\%) examples of erroneous gender concord, while there are 205/244 (84\%) examples of correct concord. Thirteen out of the 27 discord errors involve an erroneous form of the indefinite article (i.e., en) combined with the correct form of the prenominal determiner (i.e., det), illustrated in 14a, while there are ten examples where the correct form of the indefinite article (i.e., et) is combined with the erroneous form of the prenominal determiner (i.e., den), illustrated in 14b. Finally, there are four cases of discord that involve both correct and erroneous use of the indefinite article, illustrated in 14c. The majority of the discord errors (17/27) occur in the speech of the preschool children (Group 1).

$$
\begin{aligned}
& \text { a. en blå anker - en grå anker - det blåe ankeret (D7 4;7) } \\
& \text { a.M blue anchor(N) - a.M grey anchor(N) - the.N blue anchor(N) } \\
& \text { Target: et blått anker - et grått anker - det blåe ankeret } \\
& \text { et gult hus - et grønt hus - den grønne huset (D3 4;4) } \\
& \text { a.N yellow house }(\mathrm{N}) \text { - a.N green house(N) - the.M green house(N) } \\
& \text { Target: et gult hus - et grønt hus - det grønne huset } \\
& \text { en grønn ratt - et rødt ratt - det grønne rattet (D11 5;5) } \\
& \text { a.M green wheel(N) - a.N red wheel(N) - the.N green wheel(N) } \\
& \text { Target: et grønt ratt - et rødt ratt - det grønne rattet }
\end{aligned}
$$

In the masculine, there are 10/275 (4\%) examples of discord and 265/275 (96\%) examples of correct concord. There are no examples of erroneous concord in the masculine. In the feminine, there are 19/236 (8\%) examples of discord, 197/236 (83\%) examples of erroneous concord, and only 20/236 (9\%) examples of correct concord.

Thus, the preschool and school children in our study occasionally show individual item variation, using the same noun both with correct and erroneous gender markers. In our view, the low number of examples with gender discord in the child data indicates a problem with gender assignment, generally in identifying which nouns are neuter and 
which nouns are not. Thus we suggest that the children generally do not have a problem with what is often referred to as gender agreement, as the majority of items display concord throughout. Interestingly, even the discord cases like those illustrated in 14a,b, present partial concord within the DP as there is agreement between the indefinite article and the adjectival modifier. This is characteristic of all cases of discord in the child data.

In our calculations in previous sections, we have included all responses, also the ones that display gender discord. This may of course be somewhat misleading, as one of these forms is thus counted as correct, while the mismatch between the forms indicates that the child does not fully master the gender of that particular noun. However, we believe that the low number of examples with gender discord in the child data indicates that the children generally do not have a problem with what is often referred to as gender agreement.

\section{Results - Experiment 2: Feminine noun classes.}

\subsection{Indefinite DPs.}

Experiment 2 investigated four different classes of feminines, varying with respect to a semantic and a morphophonological cue (female referent and the ending $-e$ ). Table 7 shows the use of the feminine indefinite article $e i$ with these four subtypes of feminine nouns, and this is also visualized in Figure 4. The results are similar to what was found in Experiment 1. The children in Groups 1,2, and 3 use ei very infrequently, only between $10 \%$ and $21 \%$ for the four subclasses of nouns. Furthermore, there seems to be no age effect in the child data. The adults, on the other hand, use the feminine indefinite article ei $100 \%$, regardless of the noun class. The teenagers again constitute a middle group and use $e i$ at a rate varying between $63 \%$ and $71 \%$. Comparing the results for the feminine nouns to the neuter fillers (the indefinite article $e t$ ), we see that there is a clear difference between the two genders: The neuter is only slightly problematic for the youngest children (Groups $1 \&$ 2), being attested 87\% and 89\%. By age 11-13 (Group 3 ), the neuter has fallen into place, being attested $99 \%$ (compared to only $10 \%-18 \%$ accuracy for the feminines at this stage). Thus, there is some development with respect to the accuracy of neuter nouns in the data of the children. This is also similar to what was found in Experiment 1, although the accuracy rate for the neuter nouns is slightly higher in Experiment 2 (87\% vs. 79\% respectively for the participants in Group 1). However, as in Experiment 1, the differences between Groups 1, 2, and 3 are not significant ( $p=0.891$ for Group 2 and $p=0.903$ for Group 3, compared to Group 1).

\begin{tabular}{|l|l|l|l|l|l|}
\hline Group/Age & Female -C & Female -e & Non-female -C & Non-female -e & Neuter \\
\hline Group 1 & $18 \%$ & $18 \%$ & $17 \%$ & $15 \%$ & $87 \%$ \\
$3 ; 6-6 ; 0$ & $26 / 141$ & $25 / 138$ & $25 / 147$ & $22 / 149$ & $96 / 110$ \\
\hline Group 2 & $21 \%$ & $17 \%$ & $16 \%$ & $14 \%$ & $89 \%$ \\
$6 ; 6-8 ; 2$ & $27 / 127$ & $22 / 127$ & $20 / 125$ & $15 / 107$ & $74 / 83$ \\
\hline Group 3 & $16 \%$ & $18 \%$ & $10 \%$ & $10 \%$ & $99 \%$ \\
$11 ; 9-12 ; 8$ & $22 / 136$ & $26 / 141$ & $14 / 142$ & $14 / 140$ & $139 / 140$ \\
\hline Group 4 & $70 \%$ & $71 \%$ & $64 \%$ & $63 \%$ & $99 \%$ \\
$18-19$ & $132 / 189$ & $137 / 192$ & $129 / 201$ & $120 / 192$ & $193 / 195$ \\
\hline Group 5 & $100 \%$ & $100 \%$ & $100 \%$ & $100 \%$ & $100 \%$ \\
$31-64$ & $159 / 159$ & $155 / 155$ & $163 / 163$ & $164 / 164$ & $154 / 154$ \\
\hline
\end{tabular}

Table 7. Experiment 2: Accuracy of gender agreement on indefinite articles. 


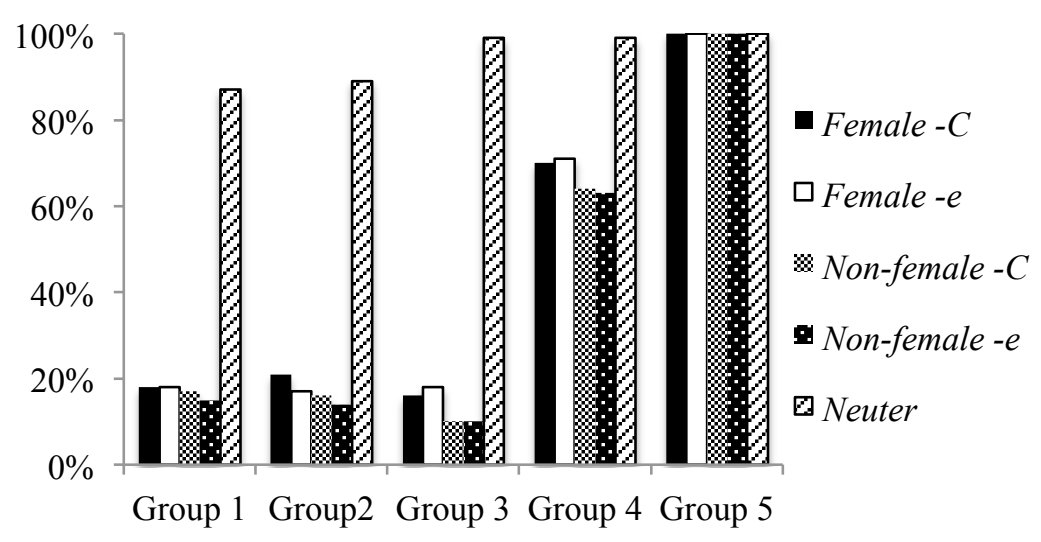

Figure 4. Experiment 2: Accuracy of gender agreement on indefinite articles.

Figure 4 also shows that the accuracy rates with feminine nouns denoting females (the first two columns) are somewhat higher than for nouns referring to non-female items (the next two columns) in Groups 1, 2, 3, and 4. A binomial mixed-effects model reveals that semantics has a weak effect in our data, in that the accuracy rates for the two groups of nouns with female reference are significantly different from the accuracy rates for the groups with non-female reference $(p=0.0025)$. However, there is no difference in the accuracy rates for feminine nouns ending in $-e$ (the second and fourth columns) versus nouns ending in a consonant (the first and third columns) in any of the groups of speakers. This observation is also confirmed by the statistical analysis $(p=0.8110)$. Thus, while semantics seems to have a weak effect on gender marking, morphophonology clearly does not. The non-effect of the morphophonological cue may be related to the change in the dialect from the $-a$ to the standard $-e$ ending, mentioned in section 2.1. We return to this in section 7 .

Again, we may have a look at some details behind the overall figures. Table 8 demonstrates the individual speaker preferences for all four subclasses of feminine nouns. As in Experiment 1 (Table 5), the majority of children (Groups 1, 2, and 3) prefer to use only the masculine form en (25/39 speakers). All the adult speakers in Group 5, on the other hand, use only the feminine form ei. Among the 18-19-year-olds (Group 4), the majority (10/17) use ei and en interchangeably. Thus, the children are very different from the adults, while the production of the teenagers is again somewhere in between.

\begin{tabular}{|l|l|l|l|}
\hline Group/Age & ei only & ei \& en & en only \\
\hline Group 1: 3;6-6;0 & $1 / 15$ & $6 / 15$ & $\mathbf{8 / 1 5}$ \\
\hline Group 2: 6;6-8;2 & $1 / 12$ & $2 / 12$ & $\mathbf{9 / 1 2}$ \\
\hline Group 3: $11 ; 9-12 ; 8$ & $1 / 12$ & $3 / 12$ & $\mathbf{8 / 1 2}$ \\
\hline Group 4: $18-19$ & $6 / 17$ & $\mathbf{1 0} / \mathbf{1 7}$ & $1 / 17$ \\
\hline Group 5: $31-64$ & $\mathbf{1 4 / 1 4}$ & $0 / 14$ & $0 / 14$ \\
\hline
\end{tabular}

Table 8. Experiment 2: The use of the indefinite articles ei (FEM) and en (MASC) with feminine nouns, $\mathrm{N}$ participants/Total.

\subsection{Double definite DPS.}

Our results for double definite DPs in Experiment 2 are identical to our findings in Experiment 1: In the feminine nouns, both the prenominal determiner den and the suffix $-a$ are used roughly $100 \%$ across all subclasses of nouns by all children and adults, while 
there is a slight delay in the neuter determiner in the two youngest groups of children. This is shown in Tables 9 and 10.

\begin{tabular}{|l|l|l|l|l|l|}
\hline \multirow{2}{*}{$\begin{array}{l}\text { Group } / \\
\text { Age }\end{array}$} & Female -C & Female -e & Non-female -C & Non-female -e & Neuter \\
\cline { 2 - 6 } & den & den & den & den & det \\
\hline Group 1 & $92 \%$ & $99 \%$ & $99 \%$ & $97 \%$ & $90 \%$ \\
$3 ; 6-6 ; 0$ & $72 / 78$ & $75 / 76$ & $83 / 84$ & $84 / 87$ & $75 / 83$ \\
\hline Group 2 & $100 \%$ & $100 \%$ & $98 \%$ & $95 \%$ & $90 \%$ \\
$6 ; 6-8 ; 2$ & $57 / 57$ & $56 / 56$ & $55 / 56$ & $58 / 61$ & $43 / 48$ \\
\hline Group 3 & $100 \%$ & $100 \%$ & $100 \%$ & $100 \%$ & $100 \%$ \\
$11 ; 9-12 ; 8$ & $61 / 61$ & $62 / 62$ & $68 / 68$ & $62 / 62$ & $67 / 67$ \\
\hline Group 4 & $100 \%$ & $100 \%$ & $100 \%$ & $100 \%$ & $100 \%$ \\
$18-19$ & $82 / 82$ & $79 / 79$ & $93 / 93$ & $88 / 88$ & $100 / 100$ \\
\hline Group 5 & $100 \%$ & $100 \%$ & $100 \%$ & $100 \%$ & $100 \%$ \\
$31-64$ & $60 / 60$ & $59 / 59$ & $70 / 70$ & $77 / 77$ & $80 / 80$ \\
\hline
\end{tabular}

Table 9. Experiment 2: Accuracy of gender marking on the prenominal determiner in double definite DPs.

\begin{tabular}{|l|l|l|l|l|l|}
\hline \multirow{2}{*}{ Group / Age } & Female -C & Female $-e$ & Non-female -C & Non-female-e & Neuter \\
\cline { 2 - 6 } & $-a$ & $-a$ & $-a$ & $-a$ & $-e t$ \\
\hline Group 1 & $93 \%$ & $92 \%$ & $98 \%$ & $93 \%$ & $97 \%$ \\
$3 ; 6-6 ; 0$ & $66 / 71$ & $61 / 66$ & $78 / 80$ & $67 / 72$ & $58 / 60$ \\
\hline Group 2 & $97 \%$ & $100 \%$ & $100 \%$ & $100 \%$ & $100 \%$ \\
$6 ; 6-8 ; 2$ & $33 / 34$ & $36 / 36$ & $54 / 54$ & $43 / 43$ & $26 / 26$ \\
\hline Group 3 & $100 \%$ & $100 \%$ & $100 \%$ & $100 \%$ & $100 \%$ \\
$11 ; 9-12 ; 8$ & $54 / 54$ & $54 / 54$ & $65 / 65$ & $57 / 57$ & $59 / 59$ \\
\hline Group 4 & $100 \%$ & $100 \%$ & $100 \%$ & $100 \%$ & $100 \%$ \\
$18-19$ & $77 / 77$ & $77 / 77$ & $87 / 87$ & $84 / 84$ & $95 / 95$ \\
\hline Group 5 & $100 \%$ & $100 \%$ & $100 \%$ & $100 \%$ & $100 \%$ \\
$31-64$ & $50 / 50$ & $49 / 49$ & $63 / 63$ & $67 / 67$ & $71 / 71$ \\
\hline
\end{tabular}

Table 10. Experiment 2: Accuracy of suffixal forms in double definite DPs.

\section{Discussion.}

The research questions for this study were formulated in section 4 and are repeated here for convenience:

1. What aspects of the gender system of Norwegian are the most problematic to acquire?

2. When is gender acquired (at 90\% accuracy)?

3. Is there a distinction between gender and declension?

4. Are children sensitive to semantic and/or morphophonological cues in gender acquisition?

5. Is the feminine gender late acquired or in the process of being lost?

The first main goal of this paper was to investigate what aspects of the Norwegian gender system are most problematic for children acquiring the Tromsø dialect, and determine how long these problems persist. In order to answer the first two research questions, we considered a large age span of child participants, with an age range 
between $3 ; 6$ and $12 ; 8$. Our findings confirm the observations made in recent experimental studies (Gagliardi 2012; Rodina \& Westergaard 2013b) that the feminine is the most vulnerable gender. In fact, our results show that feminine gender agreement is hardly produced at all, not only in the data of the preschool children, but also in the production of school children up to the age of almost 13. Furthermore, there is no age effect for the feminine noun class (Table 4). Neuter agreement is also problematic, but to a much lesser extent. For example, in the youngest age group (3;6-6;0, Group 1), where the children make most agreement errors in the neuter, there is a large contrast between the children's accuracy rates in the neuter and the feminine, $79 \%$ vs. $15 \%$. In fact, the accuracy rates of gender agreement on the feminine indefinite article decreases with age, from $15 \%$ in the data from the $3-6$-year-olds to $9 \%$ in the $6-8$-year-olds and only $7 \%$ in the 11-12-year-olds. Although this difference was not statistically significant, we think that these differences should nevertheless be explained: The younger children are presumably more exposed to input from their parents, who produce the feminine form $100 \%$. Older children, on the other hand, receive more of their input from other children, and this accumulates over time. On this perspective it is not surprising that older children in fact produce less of the feminine forms, especially if what we see here is a change in progress (see below).

A comparison of the agreement production on the indefinite article in smaller groups (3-4-year-olds, 5-6-year-olds, and 7-8-year-olds) reveals that there is an increase in target-consistent production in the neuter from around $80 \%$ at the younger ages to $91 \%$ at age 7-8. The same effect is observed for gender agreement on the prenominal determiner det, with an increase from $80 \%$ in 3-4-year-olds to $82 \%$ in 5-6-year-olds and $97 \%$ in 7-8-year-olds (see section 5.2). Thus, based on this developmental pattern, we conclude that neuter agreement falls into place (at 90\% target-consistent production) around age 7, which is quite late compared to what has been found for other languages. This delay can be attributed to the opacity of gender assignment in Norwegian. This corresponds to what has been found for Dutch (another language with arbitrary gender assignment), where neuter gender has been shown to be problematic until approximately the age of six (Blom et al. 2008; Unsworth et al. 2014; Tsimpli \& Hulk 2013).

Interestingly, neuter gender marking on indefinite articles is shown to be acquired early in German, by age three (Müller 1990, 1999), despite the fact that grammatical gender is relatively opaque (Hopp 2012). ${ }^{8}$ As pointed out by an anonymous reviewer, this fact could be explained by differences in methodology: The German studies are based on spontaneous production, while the Dutch data as well as our present study come from elicitation experiments. Nevertheless, as discussed in section 3, the use of the neuter et in the Ina corpus $(2 ; 10-3 ; 3)$ displays an error rate of $92.6 \%$, which roughly corresponds with our experimental findings for 3-to-6-year-olds, who make 79\% errors (see Table 4). At the same time, one should also consider individual differences: Recall from section 3 that the errors with neuter et constitute only $21.4 \%$ in the corpus of another Norwegian child, Ole $(2 ; 6-2 ; 10)$.

Related to the transparency of the nominal system is the question of gender assignment vs. gender agreement, as discussed in several recent studies, e.g., Bianchi (2013) and Kupisch, Akpinar \& Stöhr (2013), where non-target-consistent correspondence between different gender forms is considered to be the result of problems with gender assignment and a mismatch between forms to be due to a problem

\footnotetext{
${ }^{8}$ It should be noted that a number of phonological and semantic gender rules have been proposed for German (see Köpcke 1983; Mills 1986). However, the validity of these rules has recently been questioned (e.g., Hopp 2012).
} 
with gender agreement. As mentioned above (section 4.3), we do not think that this distinction can be made for the Norwegian data: Given the nature of the Norwegian gender system as well as previous findings (e.g., Rodina \& Westergaard 2013a, b), we assume that it is gender assignment that is difficult for Norwegian children, given the lack of transparency in the system, not the actual agreement forms, which are relatively uncomplicated. Our findings show that concord is generally target-consistent in the majority of cases (see section 5.3), and we thus have no reason to claim that the children have problems with gender agreement in Norwegian. Instead, we interpret the occasional discord found in the data to signal uncertainty on the part of the child with respect to the gender of the noun (i.e., assignment), resulting in a certain vacillation of the forms used.

With respect to research question 3, our findings also support the distinction between declension class and gender in Norwegian; see Enger (2004) based on diachronic evidence, Lødrup (2011) based on corpus data from the Oslo dialect, and Rodina \& Westergaard (2013a) based on spontaneous child data. Our new empirical data show that, while the acquisition of indefinite articles is highly problematic with feminine nouns and to some extent with the neuter, the acquisition of bound morphemes, i.e., definite articles, is nearly error-free. In the feminine this is true for all three age groups of children. As shown in Table 4, they use the feminine indefinite article ei only $15 \%$ in Group 1, 9\% in Group 2 and 7\% in Group 3, while the suffixed definite article $-a$ is used $89 \%, 95 \%$, and $100 \%$ by the same children (Table 6 ). In the neuter the contrast between the indefinite and definite articles is most clear for the youngest children (Group 1): $79 \%$ vs. 93\% respectively. This contrast is also observed in Experiment 2 (Tables 7 and 10). Similarly, in the data of the 18-19-year-olds, the unstable use of the feminine indefinite article is combined with a $100 \%$ usage of the definite $-a$ in both experiments.

Our fourth research question concerned sensitivity to the two gender cues, female reference vs. the ending $-e$. A difference between the accuracy of the noun groups expressing the two cues in the child data would indicate that one might be easier to acquire than the other, and if the same difference is found in the data of the teenagers, this would indicate that there is a change taking place, affecting one subgroup of feminine nouns more than others. Our results show that, although the difference between the two sets of nouns is slight, it is nevertheless statistically significant, indicating that female reference is a stronger cue than the ending $-e$ (see below for a possible explanation of this). This is surprising, given that previous research has shown that children are more sensitive to morphophonological than semantic cues at an early age. As we have only tested six nouns in each group and no nonce words, an alternative analysis is that this difference is simply related to lexically stored gender for individual items in the experiment, and thus, further research is needed to resolve the issue of cue strength. In any case, our results correspond to the finding in Gagliardi (2012), where the children used the feminine indefinite article slightly more with nouns denoting females than with nouns ending in $-e(46 \%$ vs. $35 \%)$. As the difference between the two groups of nouns is also found in the production of older children and the teenagers, we cannot conclude much with respect to acquisition, as the children are clearly exposed to mixed input. The teenager data also indicate that subgroups of feminine nouns are changing at slightly different rates. This corresponds to general findings that both acquisition and change take place in small steps (e.g., Rodina \& Westergaard 2012, Westergaard 2009).

This leads us to the other main goal for our study, corresponding to the last research question, i.e., whether gender is late acquired in Norwegian or whether there is a change in progress. The two studies reported here indicate that it is both. That is, Norwegian 
children have massive problems with gender, both in the feminine and the neuter. And while there is an age effect found for neuter, indicating that children do learn this at some stage (around age 7), this is not attested for the feminines, where there is no development across the three age groups $(3 ; 6-12 ; 8)$; there is in fact a decrease in accuracy. This indicates that the feminine gender is in the process of being lost in the Tromsø dialect. Some caution is of course necessary here: As there is syncretism between the feminine and masculine forms in adjectives and the prenominal determiner in double definites, our study has only considered a single gender form, the indefinite article $e i$. Thus, we may only safely conclude that the feminine indefinite article is being lost. The result of this could simply be that the syncretism in the masculine and feminine paradigms now also includes the indefinite article, en being used for both genders. In order to be able to conclude that the feminine gender is truly being lost, we would have to investigate other gender forms where there is no syncretism (yet), the main candidates being possessives and the adjective liten/lita/lite 'little' (see section 2.1 and footnote 1). We must leave this for further research. In any case, this study seems to be capturing a change that has already taken place in other Germanic languages and some dialects of Norwegian (see section 2.2), the loss of feminine gender forms. Surprisingly, this change is taking place relatively rapidly, as children up to the age of almost 13 are clearly distinct from their parent generation, adults in their thirties and forties.

It is well known that many changes have taken place in the Tromsø dialect in the last 35-40 years (e.g., Bull 1990; Nesse \& Sollid 2010). During this time, the population has more than doubled (from about 30,000 in 1970 to a little over 70,000 today) and the city has seen a considerable influx of people from other dialect areas, especially educated speakers from Eastern Norway. Furthermore, there has also been a certain influence of immigrants in recent years, i.e., second language learners of Norwegian. These are typically taught a written version of Norwegian, which only has common and neuter gender. Furthermore, most of the recent changes in the Tromsø dialect have been in the direction of Eastern Norwegian, and given that the main written variety (bokmål) may be used with only common and neuter gender, the feminine seems to have become increasingly linked to something regional, less prestigious, and possibly old-fashioned. In fact, the older school children (Group 3) seem to have an awareness of this, as one of them expressed after the experiment that using the feminine form ei is considered "uncool" in that age group. This means that the loss of the feminine would be a change in the same direction as other changes currently taking place in the dialect; i.e., towards a more standard variety. Finally, a social change that may have had an effect on the language is the fact that most children today are in full-time daycare from the age of approximately one. This means that children are exposed to input from other children to a much larger extent than, say, 30 years ago - i.e., to input produced by speakers who have not fully mastered the gender system of the language. Thus, there seem to be a number of external, social factors that may have contributed to the current simplification of the gender system from three genders to (possibly) only two.

However, the language-external factors cannot explain why it is the feminine and not the neuter that is disappearing. In Rodina \& Westergaard's (2013a) corpus study, it was argued that frequency plays an important role in the acquisition process of a language with a non-transparent gender system such as Norwegian, as overgeneralizations found in the child data were always found to be to the most frequent form. Based on the dictionary frequency counts in Trosterud 2001, Rodina \& Westergaard's (2013b) experimental study also predicted that the neuter should be the most vulnerable gender in Norwegian, due to its overall low frequency. However, in that study, the data showed that the children had more problems with the feminine, findings that are now confirmed 
by the present study. In section 2.1 , we carried out a frequency count based on childdirected speech, showing that the feminine and neuter genders are attested with equally low frequencies, approximately $18-19 \%$, while the masculine is more than three times as frequent (see Table 2). These numbers may go some way towards explaining why the neuter is not more vulnerable than the feminine.

According to the frequency counts in child-directed speech then, the feminine and neuter genders should be equally vulnerable. This is clearly not the case, as indicated in the present study - as well as in the historical data from other Germanic languages and dialects showing that it is the feminine gender that is lost (see section 2.2). One must therefore consider the variation and complexity in the agreement forms for the three genders. As shown in section 2.1, the feminine shares some agreement forms with the masculine, i.e., the prenominal determiner in double definites (as we have seen in this study), as well as adjectival forms and demonstratives. This means that, while the neuter forms are salient and clearly stand out as something special, it is much more difficult to distinguish the feminine and the masculine in the acquisition process. And in the competition between masculine and feminine, frequency again becomes a factor, as the masculine is massively more frequent than the feminine in child-directed speech. The findings from the present study thus support previous claims in the literature that frequency does play a role in acquisition, but only in combination with other factors such as complexity or economy (Roeper 2007; Bentzen \& Westergaard 2007; Anderssen, Bentzen, Rodina \& Westergaard 2010; Anderssen \& Westergaard 2010).

Another reason why the feminine may be lost in the Tromsø dialect (suggested to us by Øystein A. Vangsnes) is that the morphophonologial cue for feminine is also being lost, in that the relevant feminines are changing the ending in the indefinite from $-a$ to $-e$ (see section 2.1). That is, feminines that used to end in -a, e.g., ei dama 'a lady', ei skjorta 'a shirt', ei pcera 'a pear', are now often pronounced with the -e ending, i.e., ei dame, ei skjorte, ei pore (see Rodina \& Westergaard 2013a). Because of the special status of the $-a$ ending, the ending $-e$ in this dialect has traditionally been a cue for masculine (e.g., en pinne 'a stick', en bolle 'a bowl', en vase 'a vase'). This means that the new form of these originally feminine nouns contributes to their change to masculine gender. In order to find out whether the ending of these nouns could be a factor for the choice of gender form, we did a search across the five participant groups in the results of Experiment 1, where there were five relevant nouns in this category: bøtte/bøtta 'bucket', kake/kaka 'cake', kåpe/kåpa 'coat', såpe/såpa 'soap', and dyne/dyna 'blanket'. This investigation shows that the new $-e$ forms are produced $100 \%(51 / 51), 97 \%$ (73/75), 98\% (100/102), 90\% (126/130), and 79\% (81/103) across the five age groups. This means that the change in the noun endings clearly precedes the loss of the gender forms: For example, the adults produce the old - $a$ form only $21 \%$, but the feminine indefinite article ei $99 \%$ (Table 4). Nevertheless, these results also show that there is a general correlation between the ending and the gender form used, in that the more the speakers use the old - $a$ form, the more they also use the feminine gender form.

With respect to the distinction between gender agreement and declensional forms, the present study has confirmed findings attested in previous work: Bound morphemes such as the declensional suffixes are early acquired, while gender agreement on other targets than the noun itself are typically overgeneralized and become target-consistent relatively late in the acquisition process (around the age of 7). When a historical change is taking place, therefore, the gender forms are much more vulnerable than the declensional endings. This means that aspects of the acquisition process may explain the pattern found in other dialects that have already undergone the change, i.e., Oslo (Lødrup 2011) and Nordreisa and Kåfjord (Conzett, Johansen \& Sollid 2011), see 
section 2.2. In these dialects feminine gender agreement has been lost, while the declension is generally retained, as illustrated in 2 , repeated here for convenience.

$$
\begin{aligned}
& \text { en bok } \quad-\text { boka } \\
& \text { a.COMM book (COMM) - book.DEF } \\
& \text { 'A book - the book.' }
\end{aligned}
$$

This means that the result of this process is a simplification in the gender system from three to two genders, common and neuter. However, this is accompanied by an added complexity in the declension system, as common gender nouns now have two declensional patterns, one corresponding to the originally masculine nouns and the other to originally feminine nouns, as illustrated in $15 \mathrm{a}, \mathrm{b}$ :

$$
\begin{aligned}
& \text { a. en bil - bilen } \\
& \text { a.COMM car - car.DEF } \\
& \text { 'A car - the car.' } \\
& \text { b. en dame - dama } \\
& \text { a.COMM lady - lady.DEF } \\
& \text { 'A lady - the lady.' }
\end{aligned}
$$

\section{Summary and Conclusion.}

In this article, we have investigated the production of gender and declension in a Norwegian dialect (Tromsø) in five different age groups of speakers; pre-school children, two groups of school children, teenagers, and adults. Two experimental studies have been carried out, testing the use of indefinite articles as well as double definite forms, one focusing on all three genders, the other on four subgroups of the feminine expressing two cues, female reference and the ending $-e$. Based on the nature of the Norwegian gender system as well as previous research, our main research questions concerned the following issues: Identification of the main problems in gender acquisition, the age of acquisition, the distinction between gender and declension, sensitivity to gender cues, and the question whether there is a historical change in progress (loss of the feminine). The findings show that there is considerable overgeneralization of masculine forms in the child data to both the feminine and the neuter, argued to be due to the lack of transparency in the system. The neuter gender seems to be acquired (at 90\% accuracy) around the age of 7, making gender a late acquisition in Norwegian compared to other languages. The feminine gender (represented by the indefinite article $e i$ ), on the other hand, is hardly used at all in the children's production, while the adults use it 100\% and the teenagers around $60-70 \%$. At the same time, declensional endings (represented by the suffixal definite article) are acquired early in all three genders. With respect to the sensitivity to gender cues, we find that nouns with female reference appear somewhat more often with feminine forms than nouns ending in $-e$. We interpret these findings as an ongoing change in progress, involving loss of the feminine indefinite article, possibly also feminine gender altogether, affecting subclasses of feminine nouns at slightly different rates. The change is presumably due to sociolinguistic factors, but we argue that the nature of the change is due to the process of language acquisition, the relevant factors being syncretism, frequency, lack of transparency, as well as early acquisition of declensional forms (bound morphemes) compared to agreement. The result of this ongoing change is a simplification in the gender category and a corresponding added complexity in the declensional system. 


\section{REFERENCES}

Anderssen, Merete. 2006. The Acquisition of Compositional Definiteness in Norwegian. Doctoral dissertation, University of Tromsø.

Anderssen, Merete, and Marit Westergaard. 2010. Frequency and economy in the acquisition of variable word order. Lingua 120.11, 2569-2588.

Anderssen, Merete, Kristine Bentzen, Yulia Rodina, and Marit Westergaard. 2010. The Acquisition of Apparent Optionality: Word Order in Subject and Object shift Constructions in Norwegian. Variation in the Input: Studies in the Acquisition of Word Order. [Studies in Theoretical Psycholinguistics 39], ed. by Merete Anderssen, Kristine Bentzen \& Marit Westergaard, 241-270, Springer Verlag.

Bianchi, Giulia. 2013. Gender in Italian-German bilinguals: A comparison with German L2 learners of Italian. Bilingualism: Language and Cognition 16, 538-557.

Blom, Elma, Daniela Polišenska, and Fred Weerman. 2008. Articles, adjectives, and age of onset: The acquisition of Dutch grammatical gender. Second Language Research 24, 297-332.

Bull, Tove. 1990. Tromsø bymål [The Tromsø dialect]. Den store dialektboka, ed. by Ernst Håkon Jahr, 217-221. Oslo: Novus.

Conzett, Philipp, Åse Mette Johansen, and Hilde Sollid. 2011. Genus og substantivbøying i nordnorske språkkontaktområder [Grammatical gender and declension in language contact areas in North Norway] Nordand Tidsskrift for andrespråksforskning 6.1, 35-71.

Corbett, Greville G. 1991. Gender. Cambridge: Cambridge University Press.

Enger, Hans-Olav. 2004. On the relation between gender and declension: A diachronic perspective from Norwegian. Studies in Language 28:1, 51-82.

Faarlund, Jan Terje, Svein Lie, and Kjell-Ivar Vannebo. 1997. Norsk referansegrammatikk [A reference grammar of Norwegian]. Oslo: Universitetsforlaget.

Gagliardi, Annie. 2012. The Fundamentals of Language Acquisition. Doctoral dissertation, University of Maryland.

Haugen, Einar. 1966. Language Conflict and Language Planning: The Case of Modern Norwegian. Cambridge, MA: Harvard University Press.

Hockett, Charles F. 1958. A Course in Modern Linguistics. New York: MacMillan.

Hopp, Holger. 2012. Grammatical gender in adult L2 acquisition: Relations between lexical and syntactic variability. Second Language Research 29, 33-56.

Jahr, Ernst Håkon. 1998. Sociolinguistics in historical language contact: The Scandinavian languages and Low German during the Hanseatic period. Language Change: Advances in Historical Sociolinguistics, ed. by Ernst Håkon Jahr, 119-113. Berlin: Mouton de Gruyter.

Jahr, Ernst Håkon. 2001. Historical sociolinguistics: The role of Low German language contact in the Scandinavian typological split of the late Middle Ages. Lingua Posnaniensis 43: 95-104.

Karmiloff-Smith, Annette. 1979. A Functional Approach to Child Language: A Study of Determiners and Reference. Cambridge: Cambridge University Press.

Köpcke, Klaus-Michael. 1983. Die kognitive Organisation der Genuszuweisung zu den einsilbigen Nomen der deutschen Gegenwartssprache [The cognitive organisation of gender assignment to monosyllabic nouns in present-day German]. Zeitschrift für germanistische Linguistik 11, 166-182. 
Kupisch, Tanja, Natascha Müller \& Katja F. Cantone. 2002. Gender in monolingual and bilingual first language acquisition: Comparing Italian and French. Lingue e Linguaggio 1, 107-149.

Kupisch, Tanja, Deniz Akpinar \& Antje Stöhr. 2013. Gender assignment and gender agreement in adult bilinguals and second language learners of French. Linguistic Approaches to Bilingualism 3:2, 150-179.

Levy, Yonata. 1983. It's frogs all the way down. Cognition 15, 75-93.

Lødrup, Helge. 2011. Hvor mange genus er det i Oslo-dialekten? [How many genders are there in the Oslo dialect?]. Maal og Minne 2, 120-36.

Mills, Anne E. 1986. The Acquisition of Gender: A Study of English and German Grammatical Development. Berlin: Springer.

Müller, Natascha. 1990. Developing two gender assignment systems simultaneously. Two First Languages: Early Grammatical Development in Bilingual Children, ed. by Jürgen M. Meisel, 193-234. Amsterdam: John Benjamins.

Müller, Natascha. 1999. Gender and number in acquisition. In Barbara Unterbeck \& Matti Rissanen (ed.), Gender in Grammar and Cognition [Trends in linguistics. Studies and monographs 124], 351-399. Berlin/New York: De Gruyter.

Nesse, Agnete, and Hilde Sollid. 2010. Nordnorske bymål i et komparativt perspektiv [North Norwegian urban dialects in a comparative perspective]. Maal og Minne 1, 139-160.

Plunkett, Kim, and Sven Strömquist. 1992. The acquisition of Scandinavian languages. The Crosslinguistic Study of Language Acquisition, ed. by Dan I. Slobin, 457-556. Hillsdale, NJ: Lawrence Erlbaum Associates.

Rodina, Yulia. 2014. Variation in the input: Child and caregiver in the acquisition of grammatical gender in Russian. Language Sciences 43, 116-132.

Rodina, Yulia, and Marit Westergaard. 2012. A cue-based approach to the acquisition of grammatical gender in Russian. Journal of Child Language 39.5, 1077-1106.

Rodina, Yulia, and Marit Westergaard. 2013a. The acquisition of gender and declension class in a non-transparent system: Monolinguals and bilinguals. Studia Linguistica 67.1, 47-67.

Rodina, Yulia, and Marit Westergaard. 2013b. Two gender systems in one mind: The acquisition of grammatical gender in Norwegian-Russian bilinguals. Hamburg Studies on Linguistic Diversity 1 [Multilingualism and Language Diversity in Urban Areas: Acquisition, identities, space, education], ed. by Peter Siemund, Ingrid Gogolin, Monika Edith Schulz, and Julia Davydova, 95-126, Amsterdam: John Benjamins.

Roeper, Tom. 2007. What frequency can do and what it can't. Frequency effects in language acquisition: Defining the limits of frequency as an explanatory concept [Studies on Language Acquisition], ed. by Insa Gülzow and Natalia Gagarina, 23-48. Mouton de Gruyter, Berlin.

Rowlett, Paul. 2007. The Syntax of French. Cambridge: Cambridge University Press.

Stöhr, Antje, Deniz Akpinar, Giulia Bianchi, and Tanja Kupisch. 2012. Gender marking in L2 learners and Italian-German bilinguals with German as the weaker language. Multilingual Individuals and Multilingual Societies, ed. by Kurt Braunmüller \& Christoph Gabriel, 153-170. Amsterdam: John Benjamins.

Torp, Arne. 2005. The Nordic languages in the 19th century I: Phonology and orthography. Nordic Languages. An International Handbook of the History of the North Germanic Languages, Vol. 2, ed. by Oscar Bandle, Kurt Braunmüller, ErnstHåkon Jahr, 1425-1436. Walter de Gruyter, Berlin. 
Trosterud, Trond. 2001. Genustilordning i norsk er regelstyrt. Norsk Lingvistisk Tidsskrift 19, 29-57.

Trudgill, Peter. 2013. Gender maintenance and loss in Totenmålet, English, and other major Germanic varieties. In Search of Universal Grammar: From Old Norse to Zoque, ed. by Terje Lohndal, 77-107. Amsterdam: John Benjamins.

Tsimpli, Ianthi, and Aafke Hulk. 2013. Grammatical gender and the notion of default: Insights from language acquisition. Lingua 137, 128-144.

Unsworth, Sharon, Froso Argyri, Leonie Cornips, Aafke Hulk, Antonella Sorace, and Ianthi Tsimpli. 2014. The role of age of onset and input in early child bilingualism in Greek and Dutch. Applied Psycholinguistics 35, 765-805.

Vanvik, Arne. 1971. The phonetic-phonemic development of a Norwegian child. Norsk Tidsskrift for Sprogvidenskap 24, 269-325.

Venås, Kjell. 1993. On the choice between two written standards in Norway. Language Conflict and Language Planning, ed. by Ernst Håkon Jahr, 263-278. Berlin/New York: Mouton de Gruyter.

Vikør, Lars S. 1995. The Nordic Languages: Their Status and Interrelations. Nordic Language Secretariat Publication no. 14. Oslo: Novus Press.

Westergaard, Marit. 2009. Microvariation as diachrony: A view from acquisition. Journal of Comparative Germanic Linguistics 12.1, 49-79.

Westergaard, Marit, and Kristine Bentzen. 2007. The (Non-) Effect of Input Frequency on the Acquisition of Word Order in Norwegian Embedded Clauses. Frequency Effects in Language Acquisition: Defining the Limits of Frequency as an Explanatory Concept, [Studies on Language Acquisition], ed. by Insa Gülzow, and Natalia Gagarina, 271-306. Berlin/New York: Mouton de Gruyter. 